\title{
Liberalismo e Multiculturalismo: debates em torno do indivíduo ${ }^{1}$
}

\author{
Liberalism and Multiculturalism: debates around \\ the individual
}

\section{Joyce Miranda Leão Martins*1}

\section{Palavras-chave Indivíduo; Liberalismo; \\ Multiculturalismo; \\ Teoria política; Filosofia política.}

\section{Keywords: Individual; Liberalism; \\ Multiculturalism; \\ Political Theory; Political Philosophy.}

\begin{abstract}
Resumo: O artigo analisa a concepção de indivíduo que aparece na obra Uma Teoria da Justiça (2008), de John Rawls, e no texto Política de Reconhecimento (1994), de Charles Taylor. Estudado e pensado pela filosofia, em geral, o indivíduo emerge na teoria política como importante ponto de partida para a reflexão dos direitos, da justa organização da vida social e do papel do Estado. Desse modo, compreender o "self" se torna uma preocupação, também, para os estudiosos da política. Neste trabalho, vai se discorrer sobre o embate entre o "eu" que existe antes do social versus o "eu" que só pode existir com e partir dos outros. Pretende-se, aqui, demonstrar a compreensão do "eu" por liberais igualitários e por multiculturalistas, observando como essas noções sobre o ser particular foram responsáveis pelas distintas visões de organização estatal, bem como pelas diferentes concepções de justiça.
\end{abstract}

\begin{abstract}
The article analyses the concept of individual that appears in the work A Theory of Justice (2008), by John Rawls, and in the text The Politics of Recognition (1994), by Charles Taylor. Studied and thought by philosophy, in general, the individual emerges in political theory as an important point of departure for the reflexion of the rights, the fair organization of social life and the role of the state. In this way, understanding the "self" becomes a concern, also, to the scholars of politics. In this work, we will address about the clash between the "I" that exists before the social versus the "I" which can only exist with and from others. It is intended, here, to demonstrate the understanding of "I" by liberal egalitarians and by multiculturalists, observing how
\end{abstract}

\footnotetext{
${ }^{1}$ Recebido em 18/12/2014 e aceito para publicação em: 18/05/2015.

*1 Mestre em Sociologia pela Universidade Federal do Ceará (UFC). Doutoranda do Programa de Pós-Graduação em Ciência Política da Universidade Federal do Rio Grande do Sul (UFRGS). E-mail: joycesnitram@yahoo.com.br.
} 
these notions about the particular being were responsible for the distinct visions of state organization, as well as by different conceptions of justice.

\section{Introdução}

A "descoberta do indivíduo" colaborou para o questionamento ocidental do absolutismo e de uma sociedade com papéis pré-determinados. Houve estágios, no desenvolvimento da humanidade, em que as palavras indivíduo e sociedade não possuíam sentido, pois nem sequer existiam. Deixando à margem o esforço de distanciamento de termos que hoje são comuns, e utilizados com frequência, é fácil imaginar que eles devem sua existência à evolução da língua e à percepção de que existe um eu e os outros. De acordo com Elias, "não havia nenhum equivalente de indivíduo nas línguas antigas [...]. A persona latina referia-se a algo muito específico e tangível. Dizia respeito, antes de mais nada, às mascaras dos atores, através das quais eles proferiam sua fala". (1994, p.131). Ainda que persona possa servir como um equivalente ao indivíduo moderno, aquela palavra nada tinha do nível de generalidade do termo atual.

A nova compreensão de identidade, surgida no final do século XVIII, permitiu a mudança da política de honras (ligada a preferências, vistas na exibição de títulos de nobreza) para uma política de dignidade, na qual todos os cidadãos deveriam ter direitos e privilégios iguais (TAYLOR, 1994). O objetivo dessa última política era evitar que os cidadãos fossem divididos entre os de "primeira" e os de "segunda" classe.

É a emergência do indivíduo e a percepção deste como sujeito dotado de direitos (visão estimulada pela Revolução Francesa) que possibilita a elaboração de teorias da justiça nas quais esta aparece como equitativa: o Estado não é uma criação de Deus, mas um acordo entre indivíduos que teriam igual poder decisório em um estado de natureza.

O artigo pretende fazer breve análise dessa noção de indivíduo em Rawls, que perpassa sua obra Uma Teoria da Justiça (2008), e em Taylor, a partir da Política de Reconhecimento (1994). Para isso, é preciso fazer, antes, uma distinção fundamental entre os autores: enquanto Rawls elabora uma teoria para o Estado justo, Taylor pretende aprofundar essa teoria, sem criar modelo novo.

Acredita-se que a comparação é possível porque se prende, como já dito, a um aspecto do pensamento dos dois: a concepção de indivíduo. Kymlicka afirma que o debate sobre "as fronteiras do eu" é uma questão que cabe à filosofia da mente (2006, p.275). Entretanto, o eu, quando influencia a visão de Estado e sociedade, faz parte do interesse da teoria política. Desse modo, parte-se, aqui, de duas indagações: como o indivíduo é visto dentro das teorias 
liberal $^{2}$ e multiculturalista?; Como a noção de indivíduo colabora com a visão sobre o papel do Estado na filosofia política moderna?

Vale salientar que o indivíduo aparece de maneira bem mais nítida no texto de Taylor, visto que é o motivo que desencadeia as críticas desse autor em relação a Rawls. Da Teoria da Justiça (2008), desse último, pode-se perceber que há a idealização de uma organização social baseada em uma justiça equitativa, que não identifica idiossincrasias em seus procedimentos. Taylor, ao contrário, vai afirmar que não há justiça sem reconhecimento das diferenças: seria necessário saber mais do indivíduo, analisar seu contexto, para elaborar leis que fossem justas.

A tese de Taylor (que pretende aprofundar o liberalismo igualitário, ao invés de se opor a ele) serve para contextos localizados, enquanto os escritos de Rawls têm posição mais universalizante. Por que, então, seria preciso "suspender" as diferenças (de classe, genética etc.) para a criação (e manutenção) de um Estado justo? E por que o reconhecimento dessas diferenças é que levaria a uma organização igualitária? As páginas seguintes vão procurar responder a essas questões de acordo com as visões de Rawls e Taylor.

\section{O indivíduo em Rawls}

Entender o indivíduo (e o lugar deste) dentro da teoria política de Rawls passa pela compreensão da ideia do eu na obra que aqui propomos observar. Uma Teoria da Justiça (2008) foi a tentativa de se distanciar do utilitarismo e do intuicionismo, fornecendo uma fundamentação teórica sólida para as intuições acerca do que era justo. As idéias dessas duas correntes dominavam o debate filosófico até então. De acordo com Gorowitz, antes do livro de Rawls,

o debate girou [...] em torno de disputas referentes à adequação do utilitarismo como teoria moral à luz das nossas convicções sobre direitos individuais, integridade pessoal e honestidade. Não foram discutidas as virtudes comparativas do utilitarismo como teoria moral competindo com outras, pois não se encontrou nenhuma teoria que oferecesse alternativas plausíveis e bem elaboradas. (1982 p. 269).

Enquanto o intuicionismo é uma série de idéias e princípios baseados em "intuições específicas a respeito de questões específicas" (KYMLICKA, 2006, p.64), o utilitarismo se preocupa com a maximização do bem-estar, algo que Rawls não considera fundamental para a justiça, devido não apenas ao fato de

\footnotetext{
${ }^{2}$ Há distintos tipos de liberalismo, que se distinguem quanto ao modo de intervenção do Estado na vida social e individual. Aqui, quando for utilizado somente o termo "liberal"/"liberalismo", se estará sempre fazendo referência ao liberalismo igualitário.
} 
que felicidade é subjetiva e que uns possam ter consequências piores que outros (nessa maximização), mas também porque "o utilitarismo não leva a sério a distinção entre as pessoas". (RAWLS, 2008, p.33). É essa "concepção estreita de pessoa" que, de acordo com Vita (1992), desagrada a Rawls. Inferese, assim, que o ponto de partida da teoria de Rawls tem origem na sua insatisfação com a noção utilitária de indivíduo, que oferecia uma base fraca aos direitos, visto que era aceitável que determinados indivíduos se prejudicassem em nome da felicidade da maioria.

Nitidamente, também incomodava a Rawls que as críticas ao utilitarismo fossem feitas a partir de intuições "soltas", que não conseguiam justificar suas ideias com base em princípios fixados de justiça. Para contrapor-se a esse intuicionismo, Rawls vai apoiar-se numa das "intuições morais mais poderosas do mundo ocidental: a atribuição universal da personalidade moral" (VITA, 1992). Essa concepção supõe que os indivíduos sejam capazes de ter seu próprio entendimento sobre o bem, de construir suas mais diversas concepções, e igualmente sejam capazes de respeitar as convicções dos outros.

A teoria de Rawls segue as idéias de Kant, de que somos seres racionais e livres. A liberdade estaria de acordo com a lei natural, e a nossa racionalidade seria a responsável pela elaboração de leis morais capazes de colocar ordem em nossos fins (RAWLS, 2008, p.312). O problema na argumentação de Kant é que ele "não demonstrou que agir segundo a lei moral expressa a natureza de maneiras identificáveis, de uma forma que agir com princípios contrários não o faça". (RAWLS, 2008, p.312). Para resolver a falha, Rawls imagina a situação hipotética da posição original, na qual os indivíduos deixariam a natureza "falar", na hora da criação de leis morais. O encontro com a natureza do indivíduo seria proporcionado não por um tapete mágico voador, mas pelo véu da ignorância (artifício que permite às pessoas estar cientes apenas de conteúdos abstratos sobre o mundo ${ }^{3}$, sem nenhum conhecimento de si, posição social, objetivos, visões de bem). Rawls explica: "entre as características dessa situação está o fato de que ninguém conhece seu lugar na sociedade, sua classe e seu status social; e ninguém conhece sua sorte na distribuição de recursos e habilidades naturais" (2008, p.15).

Percebe-se que a preocupação de Rawls, em "alinhar" o indivíduo à sua natureza (aquilo que faz parte dele antes de o social existir), deve-se à crença de que nela estaria a origem da liberdade e o caminho para a justiça. A busca pelo indivíduo ocorre com o sentido de encontrar explicação e justificativa para a defesa de um Estado igualitário, o qual partiria dos desejos de indivíduos

\footnotetext{
${ }^{3}$ Apesar do desconhecimento delas mesmas, as partes, na posição original, "conhecem os fatos genéricos acerca da sociedade humana. Elas entendem os assuntos políticos e os princípios da teoria econômica; conhecem a base da organização social e as leis da psicologia humana". (RAWLS, 2008, p. 167).
} 
racionais, reivindicantes de mesmos direitos e deveres, quando na ignorância de sua riqueza ou pobreza, isto é, quando na posição original.

Esse citado "lugar de origem" é definido como sendo "um status quo no qual todos os acordos firmados são justos. É uma situação na qual as partes são igualmente representadas como pessoas morais, e o resultado não é condicionado por contingências arbitrárias nem pelo equilíbrio relativo das forças sociais" (RAWLS, 2008, p.146). Na posição original, os indivíduos elaborariam princípios de justiça capazes de beneficiar a todos de modo equivalente, pois ninguém quereria, racionalmente, na visão de Rawls, aprovar princípios de maximação de felicidade, por exemplo, que pudessem prejudicar a si mesmo. O teórico afirma que em uma situação inicial equitativa, com indivíduos de mesmo poder estabelecendo acordos, os princípios de justiça escolhidos seriam equitativos (RAWLS, 2008).

Posição original junto ao véu da ignorância retoma a tradição de contrato social para "expressar da maneira mais plena, o que somos ou podemos ser, isto é, seres racionais e livres" (RAWLS, 2008, p.318). Mas Rawls não busca explicações para o surgimento da sociedade. Não interessam, ao teórico, essas suposições. Para o autor de Uma Teoria da Justiça (2008), importa encontrar um modo de pensar a realidade dada para, a partir dela, melhorar a situação dos indivíduos, em vez de aceitá-la. Enquanto o contratualismo clássico justifica a autoridade política, o contratualismo de Rawls ilustra a escolha de princípios para a estrutura básica da sociedade. $\mathrm{O}$ acordo seria firmado para manter cada indivíduo com a liberdade que teria caso sobrenomes, posses e dinheiro não interviessem no tratamento e no julgamento estatal para com os cidadãos. 0 autor explicita que o contrato "não tem a finalidade de inaugurar uma determinada sociedade ou estabelecer uma forma específica de governo [...] A idéia norteadora é que os princípios de justiça para a estrutura básica da sociedade constituem o objeto do acordo original". (RAWLS, 2008, p.13). Não sendo uma posição marcada no tempo ou em determinada época, a ela se pode voltar quando for necessário. Rawls esclarece: "a qualquer momento podemos ingressar na posição original, por assim dizer, simplesmente obedecendo a determinado método, ou seja, argumentando a favor de princípios de justiça" (2008, p.23). De acordo com o autor, "cada pessoa tem a capacidade necessária para entender quaisquer princípios adotados e agir em conformidade com eles" (2008, p.23). A finalidade dessas condições é "representar a igualdade entre os seres humanos como pessoas morais, como criaturas que têm uma concepção do próprio bem e estão capacitadas a ter um senso de justiça". (2008, p.23).

A importância dessa ilustração, para a teoria do filósofo, é que a partir dela ele mostra sua reflexão sobre a natureza primeira do indivíduo, e, em decorrência dessa natureza do indivíduo, o autor elabora princípios de justiça que estariam de acordo com o eu que existia antes de suas ideologias e 
concepções de bem, ou seja, Rawls acredita que há um indivíduo "puro", que existe antes da sociedade. Da posição original (onde se encontram os representantes das pessoas morais) decorrem os dois princípios regentes da justiça:

1) Cada pessoa deve ter um direito igual ao sistema mais extenso de iguais liberdades fundamentais que seja compatível com um sistema similar de liberdade para outras pessoas;

2) As desigualdades sociais e econômicas devem estar dispostas de tal modo que tanto (a) se possa razoavelmente esperar que se estabeleçam em benefício de todos como (b) estejam vinculados a cargos e posições acessíveis a todos (RAWLS, 2008, p.73).

Traçando linhas mais claras, o primeiro princípio mostra a primazia da liberdade na teoria de Rawls, e o segundo esclarece que a desigualdade só pode ser aceita se for para beneficiar os que estão em posição social ou natural menos favorável para realizar escolhas autônomas, que se aproximem do "eu primeiro" racional e livre. Se existe um indivíduo posicionado em situação natural melhor, o segundo princípio de justiça (princípio da diferença) orienta que esse acaso seja revertido em favor da sociedade. Para Rawls (2008), talentos, dons e defeitos não são traços do eu, mas frutos de uma loteria arbitrária, ou seja, desigualdades sociais e naturais agem "contra" a natureza do indivíduo. E, se somos todos iguais antes da sociedade nos modificar e antes de sabermos nossos talentos, é justo, na visão de Rawls, que haja uma distribuição equitativa de bens primários ${ }^{4}$, que são escassos. A justiça para ele, então, é equitativa e obedece à natureza igual dos seres humanos (como pessoas livres e racionais, que têm a capacidade de optar por seus fins).

Sendo o eu anterior aos seus fins, a justiça e a liberdade (expressões plenas do eu) são anteriores às concepções de bem, daí que um Estado defensor da liberdade e da justiça (neutro a defesa de fins) é um Estado que está de acordo com a "fonte pura" do ser, e assim se organiza para estar de acordo com essa fonte.

É a forma como Rawls enxerga os indivíduos (e as diferenças entre esses dentro da sociedade) que o leva a ter pensado o Estado tal como pensou. Através do véu da ignorância é estimulada a nossa racionalidade, lugar de encontro com nosso eu natural, posto que esse ainda não foi moldado pelas convenções e normas sociais. A importância do véu e da posição original, em Rawls, permite-nos perceber que o conhecimento de si, e do grupo social, não é critério relevante para estabelecer a justiça. E Rawls coloca como irrelevante

\footnotetext{
${ }^{4}$ Os bens primários são de tipo social (direitos, liberdade, renda, oportunidades) e natural (saúde, inteligência, vigor, talentos). (RAWLS, 2008).
} 
porque não fazem parte da constituição natural do indivíduo (essa constituição que orienta o pensamento da organização de um Estado justo no liberalismo).

Rawls teve grande importância para os estudiosos de teorias da justiça. Ele encerrou o impasse histórico entre utilitaristas e intuicionistas, e os teóricos seguintes passaram a se definir em relação a Rawls. Uma das críticas que mais teve eco, dirigidas ao filósofo, está ligada ao questionamento da existência do eu anterior aos fins. É mesmo possível haver indivíduo quando este é pensado longe de suas características particulares ${ }^{5}$ ?

\section{A visão de Taylor}

O eu liberal, para Taylor (1994), é, na verdade, um eu inexistente, pois a formação e manutenção da nossa identidade é, para ele, dialógica. Com o livro Hegel e a Sociedade Moderna, Taylor foi um dos que mais colaborou para "a tarefa de 'abrir o fogo' comunitarista contra o liberalismo" (GARGARELLA, 2008, p.138). O comunitarismo ${ }^{6}$ questionou a noção de indivíduo em Rawls, porque aquele aparece desvinculado de seus fins:

Tomados en conjunto, el yo desvinculado y la ética que inspiran presentan um proyecto liberador. Emancipado de los dictados de la naturaleza y de la sanción de los roles sociales, el sujeto humano se elige en soberano, en autor de los únicos significados morales que pueden existir. [...] Como sujetos individuales reales somos libres de elegir nuestras metas y fines sin estar limitados por ningún orden de este tipo, ya sea la constumbre, la tradición o el estatus heredado. [...] Esa es una promesa estimulante y el liberalismo al que da vida es quizás la expresión más plena de esa búsqueda de um sujeto capaz de definirse a si mismo que caracterizo a la ilustración. ¿ Pero es verdadera? Podemos dar sentido a nuestra vida moral y política a la luz de la imagen de nosostros mismos que requiere esa promesa? (SANDEL, 2008, p. 222).

O questionamento de Sandel mostra que, assim como Rawls contestou a concepção de pessoa do utilitarismo, por não ser "sensível às diferenças" comunitários, e depois os multiculturalistas, contestam a noção de indivíduo em Rawls. A crítica, apesar de distinta, é formulada nos mesmos termos. Não sensíveis às diferenças que afetam os indivíduos (desta vez, diferenças culturais

\footnotetext{
${ }^{5}$ Rawls poderia argumentar que na posição original não está o indivíduo em si, mas uma representação de pessoa moral. Entretanto, se é possível entrar "a qualquer momento na posição original", isso leva a crer que existiria a possibilidade dos fins ficarem "suspensos" enquanto o eu racional (e livre) toma decisões.

${ }^{6}$ Corrente de autores que se contrapunham ao liberalismo igualitário e faziam a defesa de um eu vinculado à comunidade e a valores.

7 De talento, saúde, renda.
} 
a partir das quais o eu é formado, na visão comunitarista), os liberais igualitários acabariam por perpetuar discriminações realizadas por culturas dominantes. Sandel acredita que a forma como Rawls concebe os indivíduos chega a ser prejudicial à própria teoria do filósofo igualitário, pois fragiliza a aceitação, por parte das pessoas, do princípio da diferença (aquele diz que talentos naturais e posição social são arbitrários e, por isso, devem ser redistribuídos na sociedade). Nas palavras do comunitário:

Del simple hecho de que yo, como individuo, no tenga derecho
privilegiado sobre los activos que residen accidentalmente <<aqui>>,
en mi, no se desprende que tal derecho corresponda a todo el mundo
colectivamente: no hay motivo para pensar que la ubicación de eses
activos, bajo el dominio de la sociedad, o por así decirlo, de la
humanidad en su conjunto, sea menos arbitraria desde un punto de
vista moral. Y si la arbitrariedad de su presencia en mí los descarta para
ponerlos a servicio de mis fines, no parece que exista razón para que la
arbitrariedad de su presencia en una sociedade determinada no los
descarte igualmente para ponerlos al servicio de los fines de dicha
sociedad. (SANDEL, 2008, p. 225).

O princípio da diferença é, então, um princípio de copartição. E a um eu desvinculado, a quem está negada a possibilidade de estar ligado, constitutivamente, a uma comunidade de laços morais (já que não pode pertencer a nenhuma comunidade que coloque em jogo o sujeito em si) não há motivo para compartilhar os talentos que, por sorte, possui. Essa é a visão de Sandel, que julga como injusta a distribuição de talentos e fortunas em uma sociedade na qual o eu não tem vínculos morais.

Na Política de Reconhecimento (1994), Taylor segue as críticas elaboradas pela percepção comunitarista e as amplia no multiculturalismo, que se distingue da primeira percepção ao buscar, a partir do próprio liberalismo, um modo de mostrar que a garantia dos direitos básicos passa pela defesa de distintas culturas da sociedade. Isso porque as culturas estão também nos indivíduos, que não são capazes de existir sozinhos, mas existem em relação a outros e com outros: "temos de tomar em consideração um aspecto definitivo da condição humana, praticamente invisível por culpa da tendência esmagadoramente monológica que tem caracterizado a filosofia moderna dominante. Refiro-me ao seu caráter fundamentalmente dialógico". (TAYLOR, 1994, p. 52).

Para os multiculturalistas, esse eu formado com o outro é o nosso próprio eu e dele não se pode desvencilhar-se:

Temos de desenvolver as nossas próprias opiniões, atitudes, posições em relação às coisas, o que implica uma boa dose de reflexão solitária. 
Mas não é assim que se passa com as questões importantes como a nossa identidade. Definimo-la sempre em diálogo sobre, e, por vezes, contra, as coisas que os nossos outros-importantes querem ver assumidas em nós. Mesmo depois de deixarmos pra trás alguns desses outros-importantes - os nossos pais, por exemplo - e de eles desaparecerem das nossas vidas, o diálogo com eles continua para o resto das nossas vidas. (TAYLOR, 1994, p. 53).

Os nossos fins e laços comunitários nos tornam indivíduos com determinadas crenças, em determinada sociedade. São, por exemplo, os fins e as crenças que fazem alguém se sentir brasileiro e não japonês. Essas distinções formam o eu particular, com seus laços morais, e o fazem ser um determinado sujeito e não outro.

Se na Política do Reconhecimento (1994) o indivíduo se constrói em relação a outro, fica claro que, na visão de Taylor, o eu não é anterior aos seus fins, ao invés disso, constrói-se também a partir e por causa desses fins, ou seja, o eu não possui dimensões que possam ser separadas, mesmo que em situações hipotéticas, com o objetivo de se pensar em uma justa organização e função estatal. A própria justiça está ligada a esses fins, às distintas concepções de bem de uma sociedade. Desse modo, o Estado justo do multiculturalismo não pode ser semelhante ao Estado do liberalismo igualitário, pois compreender os indivíduos de forma distinta gera percepções diferentes de justiça e, consequentemente, interferem nas exigências feitas ao Estado. A reivindicação de que todas as pessoas deveriam ser reconhecidas por suas identidades únicas dá origem a uma política da diferença, no lugar daquela política de dignidade que Taylor julga estar representada em Rawls. A identidade, ao invés de ser respeitada com o reconhecimento da igualdade do indivíduo como pessoa moral (caso do liberalismo igualitário), passa a ser respeitada com o reconhecimento das diferenças.

Seguindo o pensamento de que eu me construo a partir dos meus fins, e das minhas concepções de bem (tiradas da sociedade em que vivo), o Estado precisaria abrir mão da neutralidade ${ }^{8}$ para agir em defesa dos princípios ${ }^{9}$ dessa sociedade que faz parte da constituição do meu eu. A necessidade de que isso

\footnotetext{
${ }^{8}$ Alguns autores que, como Taylor, acreditam ser o multiculturalismo um "desdobramento" do liberalismo igualitário conseguem imaginar o Estado multicultural como neutro, desde que seja assim tendo como finalidade a sobrevivência cultural de qualquer pessoa (WALZER, 1994, p.120). Pensamento que, de algum modo, parece seguir a conclusão de Taylor de que culturas devem ser consideradas igualmente, pelo Estado, sem classificação de superior ou inferior. Esse debate (se o Estado multicultural pode ser neutro) não será aprofundado aqui e se continuará destacando o Estado liberal como neutro, visto que coloca a questão da sobrevivência cultural nas mãos dos indivíduos, mesmo que assim fazendo esteja, na verdade, refletindo uma cultura hegemônica (crítica multiculturalista).

${ }^{9}$ No caso do multiculturalismo, esses princípios não foram pensados racionalmente. São dados pelas diferentes tradições.
} 
ocorra acontece porque a democracia, que trouxe consigo a ideia de reconhecimento igualitário e de princípios universalistas, não teria, de acordo com Taylor (1994), cumprido sua promessa de dotar os cidadãos dos mesmos direitos e benesses, visto que estaria negligenciando especificidades individuais. A exigência de uma política de reconhecimento por parte de grupos feministas, nacionalistas e outros grupos minoritários ou subalternos mostra que o ideal liberal de igualdade não satisfez a todos os cidadãos.

A tese da política de reconhecimento afirma que a identidade é formada, em parte, pela existência ou inexistência de reconhecimento, ou ainda, por reconhecimento incorreto, permitido pela interiorização de imagens depreciativas estimuladas por determinada cultura dominante (o que ocorria com mulheres em sociedades patriarcais, por exemplo). O reconhecimento incorreto - afirmam os multiculturalistas - é uma forma de agressão e de induzir o indivíduo a uma maneira de ser distorcida, que o restringe. (TAYLOR, 1994).

Os adeptos da política de dignidade encararam a situação, nas palavras de Taylor (1994), como uma traição, uma negação do princípio igualitário que prezavam. O autor afirma que tentativas, para se chegar a um meio-termo, pretendiam demonstrar que certas medidas em favor das minorias podiam ser justificadas com base na dignidade, como vantagens competitivas em empregos e vagas nas universidades. Essas medidas, justificadas pelo fato de a discriminação histórica colocar os desfavorecidos em desvantagem, são pensadas, pelos defensores da política de dignidade, como temporárias, pois nivelariam "o campo de batalha", permitindo, posteriormente, a volta das velhas regras. A possibilidade de, futuramente, desconsiderarem-se as diferenças faria a polêmica com os multiculturalistas persistir.

Taylor afirma que as medidas citadas, tomadas com base na diferença, iriam, mais tarde, repor um espaço social que negligenciaria as distinções (TAYLOR, 1994). Apesar de ambas (política da dignidade e política da diferença) terem em comum a noção de respeito igual, parece ser indissolúvel o conflito quanto ao princípio de respeito igual, pois a primeira política exige que as pessoas sejam tratadas de forma que se ignorem as diferenças, e a segunda considera discriminatória a negação das particularidades.

Os radicais da política da diferença, segundo Taylor (1994), julgam que a visão liberal da política de dignidade acaba por ser um particularismo disfarçado de universalismo, pois, muitas vezes, alguns liberais julgam inaceitável a aplicação de direitos de acordo com contextos culturais.

Vale destacar que o multiculturalismo não deseja que a comunidade se sobressaia perante o individuo, até porque reconhece a existência de diversas culturas em um mesmo Estado. Walzer afirma que o multiculturalismo é permissivo, não determinado: 


\begin{abstract}
"Taylor escreve que os liberais do segundo tipo [multiculturalistas] 'estão dispostos a pesar a importância de certas formas de tratamento uniforme (de acordo com uma forte teoria dos direitos) contra a importância da sobrevivência cultural, e optam às vezes [...] a favor do liberalismo do primeiro tipo'" (WALZER, 1994, p. 118).
\end{abstract}

A leitura do multiculturalismo, a partir da Política de Reconhecimento (1994), parece solucionar as lacunas da teoria de Rawls e, por isso, é mister destacar que o liberalismo igualitário surgiu se insurgindo contra multiculturalismos (entendido aqui no sentido de pluralismo): "o liberalismo nasceu [...] como uma resposta aos conflitos gerados pelo 'multiculturalismo' das sociedades dos séculos XVI e XVII, isto é, como proposta de tratamento equitativo para os adeptos do catolicismo e do protestantismo sob instituições comuns" (VITA, 2002).

$\mathrm{Na}$ verdade, o liberalismo de Rawls emerge como o grito de um indivíduo oprimido por instituições que não viam direitos para aqueles que tinham opiniões diferentes da "massa", de governos e igrejas. O multiculturalismo reage ao "eu desvinculado", mas não apresenta propostas práticas para impedir que um indivíduo seja "massacrado" quando quiser pensar e agir de modo distinto do que sua nação considera bom.

A disputa em torno da noção do indivíduo e, consequentemente, da melhor concepção de Estado, parece ter ainda um longo caminho, talvez a ser seguido pelas pistas deixadas no debate entre liberais e multiculturalistas.

\title{
Conclusão
}

As discordâncias entre as visões de Rawls e de Taylor têm como pano de fundo uma disputa de longa data dentro da filosofia e das ciências humanas: a questão do indivíduo e da sociedade. De acordo com Gargarella, as discordâncias à visão do indivíduo, em Rawls, expressam as críticas que Hegel fazia a Kant:

Enquanto Kant mencionava a existência de certas obrigações universais que deveriam prevalecer sobre aquelas mais contingentes, derivadas do fato de pertencermos a uma comunidade particular, Hegel invertia essa formulação para dar prioridade aos nossos laços comunitários (2008, p. 137).

Rawls procurou explicar o momento em que o indivíduo existe de acordo com a visão Kantiana, o que ocorreria com um eu desvencilhado de seus fins. $O$ eu racional e livre teria lugar no momento em que todos os indivíduos 
estivessem em "pé de igualdade", deixando a racionalidade destacar-se diante dos fins que foram obtidos, posteriormente, à constituição do eu da natureza.

A crítica iniciada pelo comunitarismo, que discorda da visão do "eu desonerado", decerto influenciou os futuros pensamentos de Rawls, que deram origem ao Liberalismo Político, ${ }^{10}$ o qual poderia ser mantido sem que as pessoas sustentassem os valores dele. Como o artigo se ocupou somente da noção de indivíduo dentro do liberalismo igualitário e do multiculturalismo, não se fez menção a essa revisão da teoria por parte de Rawls.

Importava aqui demonstrar como as idéias em torno do indivíduo são importantes para a teoria política, visto que acarretam em distintas visões sobre o Estado e sua organização. Foi a concepção de indivíduo como ser racional, capaz de pensar numa organização estatal para além de seus valores (situação da posição original), que fez Rawls pensar na razoabilidade e aceitação (por parte de todos) de um Estado neutro, isso é, que funcionasse para garantir a autonomia diante dos diversos fins de uma sociedade.

O multiculturalismo, julgando que o eu não existe sem o outro nem pode ser compreendido distante da sociedade, concebe um Estado em que a sobrevivência cultural seja mantida. Não obstante, o indivíduo também precisa ser respeitado na sua vontade de permanecer (ou não) vivendo sob os valores de determinada comunidade. E é por isso que, em Taylor, as vantagens, na lei, para determinado grupo, só devem existir quando houver exigência de reconhecimento por parte desses mesmos grupos.

Entre liberalismo e multiculturalismo parece ainda lutar por espaço a compreensão vista em Elias (1994), de que o indivíduo (para além do aspecto tangível) e a sociedade só são possíveis devido à relação entre ambos. Defender o indivíduo de acordo com as leis e tradições da sua comunidade, ao mesmo tempo em que o protege dela, é um desafio que fica pendente e estimula o debate a prosseguir na teoria política.

\section{REFERÊNCIAS}

APPIAH, Anthony. Identidade, Autenticidade, Sobrevivência: Sociedades Multiculturais e Reprodução Social. In: Charles Taylor (org.). Multiculturalismo. Lisboa: Instituto Piaget, 1994.

ELIAS, Norbert. A Sociedade dos Indivíduos. Rio de Janeiro: Zahar, 1994.

GARGARELLA, Roberto. As teorias da justiça depois de Rawls: Um breve manual de filosofia política. São Paulo: Martins Fontes, 2008.

\footnotetext{
10 Nessa obra a liberdade ganha uma importância ainda maior sobre a igualdade. Rawls reconhece o pluralismo cultural dentro da sociedade, mas permanece recebendo muitas críticas, pois sugere que as convicções sejam deixadas de lado na hora das discussões públicas (2008).
} 
GOROWITZ, Samuel. John Rawls: Uma Teoria da Justiça. 2 ed. In: Crespigny; Minogue (orgs.) Filosofia Política Contemporânea. Brasília: Editora Universidade de Brasília, 1982.

HABERMAS, Jürgen. Lutas pelo Reconhecimento no Estado Constitucional Democrático. In: Charles Taylor (org.). Multiculturalismo. Lisboa: Instituto Piaget, 1994.

KYMLICKA, Will. A Igualdade Liberal. In: __. Filosofia Política Contemporânea: Uma Introdução. São Paulo: Martins Fontes, 2006.

KYMLICKA, Will. O Comunitarismo. In: _. Filosofia Política Contemporânea: Uma Introdução. São Paulo: Martins Fontes, 2006.

RAWLS, John. Uma Teoria da Justiça. 3 ed. São Paulo: Martins Fontes, 2008.

SANDEL, Michael J. La República Procedimental y el Yo Desvinculado. In: SANDEL, Michael J. Filsofía Pública: Ensayos Sobre Moral em Política. Barcelona: Marbot Ediciones, 2008.

TAYLOR, Charles (org). A Política de Reconhecimento. In: Multiculturalismo. Lisboa: Instituto Piaget, 1994.

VITA, Álvaro. A tarefa prática da filosofia política em John Rawls. Revista Lua Nova, n025. São Paulo: 1992.

VITA, Álvaro. Liberalismo Igualitário e Multiculturalismo (Sobre Barry, Culture and Equality). Revista Lua Nova, n55. São Paulo: 2002.

WALZER, Michael. Comentário. In: Charles Taylor (org.). Multiculturalismo. Lisboa: Instituto Piaget, 1994. 